\title{
Normalismo y mujeres. Las maestras en el Quién es Quién en La Plata (1972): trayectorias de una élite intelectual y profesional
}

Normalism and women. Teachers in the Who is Who in La Plata (1972): trajectories of intellectual and professional elite

Laura Graciela Rodríguez

Comisión Nacional de Investigaciones Cientificas y Técnicas-

Instituto de Investigación em Humanidades y Ciencias Sociales- Universidad Nacional de La Plata, Argentina

lau.g.rodrig@gmail.com

\section{ReSUMEN:}

En este artículo abordaremos un tema poco tratado aún y es el estudio de un grupo de maestras normalistas pertenecientes a distintas generaciones, que fueron consideradas parte de la élite intelectual y profesional de la ciudad capital de la provincia de Buenos Aires y por esa razón, sus nombres aparecieron en la edición del diccionario biográfico Quién es Quién en La Plata del año 1972. En este trabajo nos proponemos analizar quiénes fueron estas 31 maestras destacadas a partir de un estudio basado en esta fuente, donde relevaremos: en qué institución/es estudiaron y en qué año/s se titularon, cuál era su estatus civil, qué trabajos tuvieron y cuáles fueron sus otras actividades por fuera del ámbito laboral.

Palabras ClaVE: Normalismo, La Plata, Élites, Mujeres, Maestras.

\section{Abstract:}

In this article we will present the study of a group of normal teachers belonging to different generations, which were considered part of the intellectual and professional elite of the capital city of the province of Buenos Aires and for that reason, their names appeared in the edition of the biographical dictionary, Who's Who in La Plata of the year 1972. In this work we propose to analyze who were these 31 teachers featured from a study based on this source, where we will show: on what institution they studied and what year/s were titled, what was their civil status, jobs had and which they were their other activities.

KEYWORDs: Normal movement, La Plata, Elites, Women, Teachers.

Las maestras egresadas de las Escuelas Normales han sido estudiadas en general como un grupo profesional subordinado a los hombres en tanto funcionarios, profesores de secundaria y/o universitarios; pero también en relación a cómo lograron proyectarse en el espacio público más allá de la escuela en su rol de profesionales portadoras de un saber experto, agentes con incidencia en sus comunidades e intelectuales actuando como escritoras, periodistas, poetas y/o novelistas (Maristany, 1998; Barrancos, 2008; Billorou, 2015; Vignoli, 2015; Alvarado, 2016; Becerra, 2016; Caldo, 2018; Lionetti, 2018; Becerra, 2020). En este artículo abordaremos un tema poco tratado aún y es el estudio de un grupo de maestras normalistas pertenecientes a distintas generaciones, que fueron consideradas parte de la élite intelectual y profesional de la ciudad capital de la provincia de Buenos Aires y por esa razón, sus nombres aparecieron en la edición del diccionario biográfico Quién es Quién en La Plata del año 1972. Estos libros se han publicado periódicamente en Argentina y en otros países de Europa y América con el propósito de identificar a las élites de una nación, provincia o ciudad. En este trabajo nos proponemos analizar quiénes fueron estas 31 maestras destacadas a partir de un estudio basado en esta fuente, donde relevaremos: en qué institución/es estudiaron y en qué año/s se titularon, cuál era su estatus civil, qué trabajos tuvieron y cuáles fueron sus 
otras actividades por fueradel ámbito laboral. Consideramos además, que estos diccionarios, por el tipo de información que contienen, permiten realizar un aporte significativo a la historia social y cultural del magisterio.

Este texto está dividido en siete apartados. En el primero plantearemos qué particularidades han tenido las ediciones de los Quién es Quién en Argentina y en La Plata; en el segundo brindaremos datos contextuales sobre las maestras como grupo profesional; en los siguientes cuatro apartados presentaremos las autobiografías de las maestras y en el último, de los maestros. Pretendemos mostrar, en primer lugar, que el hecho de que las maestras fuesen consideradas parte de las élites era completamente inusual, ya que la serie de los Quién es Quién nacionales siempre incluyó a los “profesores" pero nunca a los "maestros" como categoría profesional. Asimismo, indicaremos que la mayoría de las maestras en la ciudad de La Plata eran egresadas de una institución pública considerada de élite para las mujeres: la Escuela Normal (en adelante EN) No 1 "Mary O'Graham", mientras que el resto se había recibido de maestra en otras EN públicas y privadas ubicadas en la misma ciudad y en otras localidades. En este sentido, señalaremos que las trayectorias de estas maestras exhibían cierta disponibilidad de tiempo libre y recursos, dado que pudieron realizar otros estudios, ejercer otros trabajos y dedicarse a distintas actividades, lo que las ubicaría - tanto a las casadas como a las solterasen las clases medias y medias- altas.

En segundo lugar, mostraremos que sus trayectorias estuvieron marcadas por: a) el año que se recibieron, b) los tipos de estudios, trabajos y actividades que hicieron, y c) las posibilidades de ascender a los puestos jerárquicos. En este sentido, observar los distintos recorridos que hicieron las diferentes generaciones de mujeres, nos permite pensar el cambio social y las transformaciones que atravesaron a este colectivo. Respecto al primer punto, veremos que las 17 maestras que se recibieron entre las décadas de 1910 y 1940 se dedicaron casi todas a la docencia en el nivel primario, mientras que las demás, en general más jóvenes, tuvieron otros trabajos y unas siete egresaron de la universidad entre los años de 1940 y 1970. En relación al segundo ítem, señalaremos que los cursos que hicieron, las titulaciones que obtuvieron, los otros trabajos y las actividades que realizaron, se concentraron en las áreas de enseñanza, cuidado y servicio, ámbitos que los discursos hegemónicos de género tradicionalmente le asignaron a las mujeres (Bourdieu, 2000). Sobre la tercera cuestión, mencionaremos que sus trayectorias exhibían una acentuada segregación vertical, ya que menos de la mitad de las maestras alcanzó a ocupar los más altos cargos en la carrera docente como directoras, inspectoras y/o funcionarias. Por último, reseñaremos brevemente las cinco trayectorias de maestros varones que aparecían en el Quién es Quién en La Plata, con el propósito de compararlas con sus colegas mujeres. Tal y como se menciona en otras investigaciones, constataremos que los hombres lograron ascender más rápidamente que las mujeres, independientemente de la edad o la titulación, al tiempo que estaban vinculados a otro tipo de asociaciones e instituciones.

\section{Quién es Quién en Argentina y en La Plata}

Los Quién es Quién de Argentina y de La Plata reproducían el formato de los anuarios biográficos de las élites que se venían editando en Argentina desde 1939 y en otros países como Reino Unido (1848), Estados Unidos (1898), Brasil (1948) y Francia (1953) entre otros. Coincidimos con otros analistas que sugieren que estos diccionarios biográficos parecen seguir la concepción de Vilfredo Pareto sobre las élites, retratando a "los mejores" en cada ramo de actividad (Heinz, 2011). ${ }^{1}$ El Quién es Quién en la Argentina. Biografías contemporáneas fue publicado por la Editorial Guillermo Kraft Limitada y, según decía en su sexta edición (1955), la prestigiosa Universidad de Stanford de Estados Unidos editaba un Who's Who in Latin America que reproducía para el capítulo de Argentina los nombres de la edición de Kraft: "prueba de confianza ésta que mal podría dejar de halagarnos". ${ }^{2}$ Allí se explicaba que buscaban retratar a los "hombres de calidad superior", aunque la lista siempre estaba "inevitablemente incompleta". En cada edición se incluían nuevos nombres representativos así como también, se dejaba constancia al final de los que habían fallecido. El libro, se aclaraba, informaba pero no calificaba, carecía de "finalidad utilitaria" y sólo perseguía "el propósito de colaborar en la 
noble tarea de divulgar nombres que honran a la Patria". Revisando todas las ediciones hasta los años de 1960, hemos constatado que los profesionales que estaban retratados eran los abogados, médicos, profesionales con doctorados, ingenieros, contadores públicos, arquitectos, comerciantes y militares, y en menor medida industriales, escritores, pintores y profesores universitarios, entre otros. ${ }^{3}$ No existía la categoría de "maestros" y en general, en todas las ediciones figuraban muy pocas mujeres y en la mayoría de los rubros, ninguna. ${ }^{4}$

En relación con el Quién es Quién en La Plata, hasta donde sabemos, esta edición no tuvo continuidad y es la única que se hizo sobre una ciudad y por fuera de las nacionales. Su editor, Américo P. Napolitano, sostenía en el prólogo que se incluían "figuras notables en distintos órdenes" que contribuían con su dedicación "al engrandecimiento de la Patria”, y si bien se habían omitido "otros valores destacados", eso obedecía a razones ajenas a su voluntad que esperaban subsanar para la próxima edición. El lector ha de coincidir, decía, que los incorporados conformaban "gran parte de la máquina" que movía la ciudad "en lo intelectual, lo industrial y comercial". Por su parte, el auspiciante destacaba que el diccionario se había hecho "en reconocimiento a los altos valores espirituales, profesionales, científicos y comerciales de personas que en gran medida" contribuían "al progreso de nuestra ciudad". ${ }^{5}$ De acuerdo a estas afirmaciones, las maestras fueron incluidas en esa edición porque eran vistas por sus contemporáneos formando parte de la élite intelectual y profesional local. Respecto a cómo recolectaron los datos, explicaba que el editor junto a un equipo formado por casi un centenar de colaboradores, en "su mayor parte profesionales y estudiantes universitarios", habían requerido de cada entrevistado su biografía, que reprodujeron objetivamente omitiendo solo en algunos casos y por razones de espacio, algunos hechos de "menor trascendencia". El trabajo, continuaba, había durado diez meses en los cuales realizaron la investigación previa, entrevistas, redacción, corrección, compaginación, fotografías y diagramación. Ahora bien, ¿y cómo se eligieron inicialmente a estos "notables"? El editor no lo decía, pero observando las biografías, constatamos que algunos datos se repetían. En base a ellos, deducimos que se seleccionaron a las autoridades y profesores destacados de los colegios secundarios y de las distintas Facultades de la Universidad Nacional de La Plata (UNLP), a los integrantes de las comisiones directivas de los clubes de fútbol más importantes, los colegios profesionales, las asociaciones empresariales, comerciales y de otras como el Rotary, el Jockey Club, la Sociedad Argentina de Escritores (SADE), artísticas y de beneficencia, entre otros.

En el Quién es Quién en La Plata había alrededor de 1748 biografías en total, de las cuales 1495 correspondían a hombres y 253 a mujeres. Casi todos los hombres y mujeres eran retratados, a diferencia del Quién es Quién de nación, con fotos carnet en blanco y negro. Al lado izquierdo de la foto se encontraban en letras negras el nombre y apellido y su/s titulación/es. En el texto ubicado debajo de la foto se ofrecían siempre los mismos datos: lugar y fecha de nacimiento, nombre de los padres, esposa/o, hijos, estudios, actuación y al final, el domicilio. De las 253 mujeres, 31 figuraban con la leyenda junto a la foto de "maestra normal nacional", "docente" o "educadora" (ver figuras).

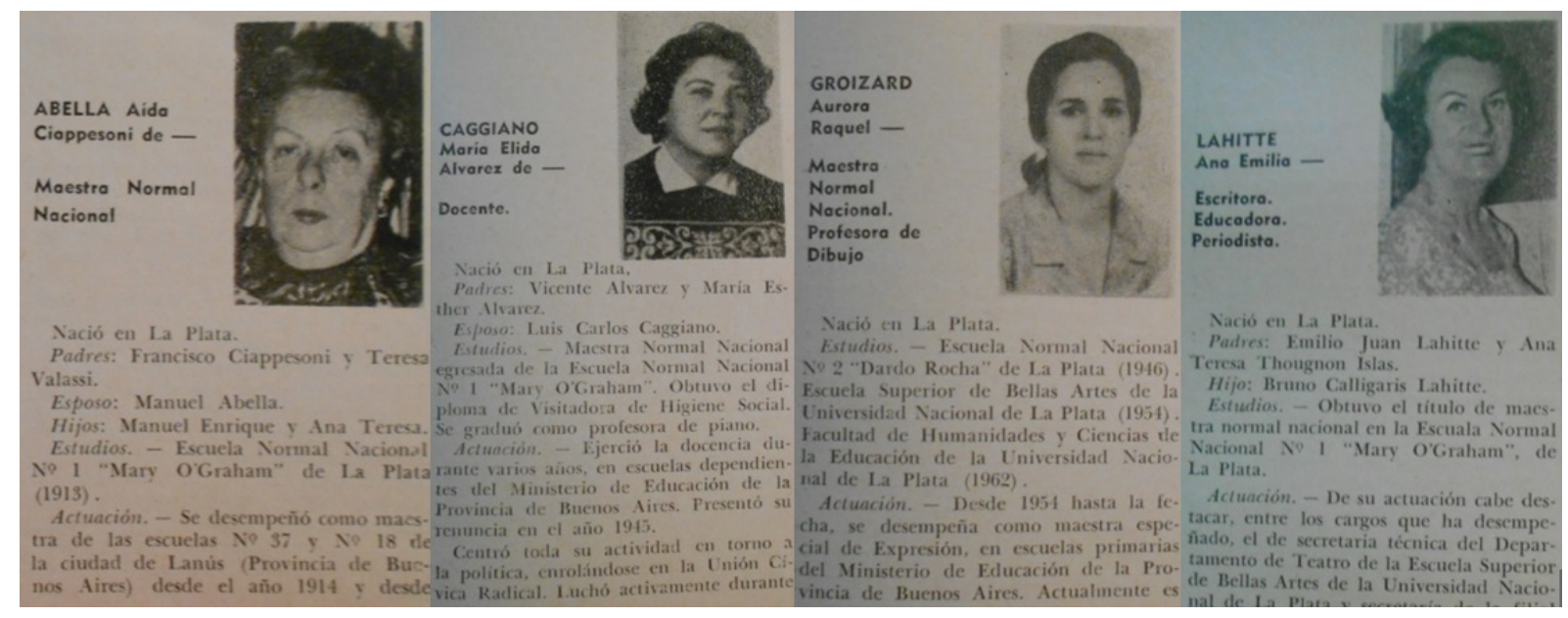


El resto de las 222 mujeres declaraban otras actividades, aunque 17 decían haber trabajado como maestras normales durante unos años. Como señalan las distintas investigaciones (ver infra), el número de tituladas universitarias siguió la tendencia de aumentar con el tiempo: entre 1910 y 1939 eran 13; 1940-1950: 44; 1951-1960: 38 y entre 1961 a 1972 se concentraban 59 egresadas universitarias. La mayoría (114) se presentaba como profesora de nivel secundario y/o universitario en distintas disciplinas: filosofía y ciencias de la educación (24), letras (22), música (12), dibujo (10), geografía e historia (8), piano (7), ciencias físico- matemáticas (6), inglés (6), ciencias biológicas (5), francés (4), educación física (3), ciencias químicas (2), danzas clásicas (2), escultura (2) y canto (1). Había además doctoras en: medicina (15), ciencias naturales (9), bioquímica y farmacia (2), veterinaria (1) y física (1); ingenieras en: agronomía (1), forestal (1), civil (1) y mecánico- electricista (1); abogadas (13), contadoras públicas (5), escribanas (2), odontólogas (2); y licenciadas en: astronomía (3), matemática (1) y química (1). Figuraban también una dietista, periodista (1), agrimensora (1), obstetra (1), psicóloga (1), una titulada en declamación y una especialista en estética infantil. ${ }^{6}$ Unas 44 mujeres aparecían sin otro título que el del nivel medio y se presentaban como pianistas, cantantes, directoras de coros, concertistas de arpa, folkloristas, bailarinas, pintoras, artistas plásticas, escultoras, actrices y "directivas” (presidentas de entidades benéficas).

\section{Las maestras en elQuién es Quién en La Plata: profesión femenina, Prestigiosa Y DE CLASE MEDIA}

Como ya mencionamos, en el Quién es Quién en La Plata aparecían 31 maestras y solo cinco maestros.7 $\mathrm{Al}$ igual que ocurrió en otros países, la profesión de maestra concentró, desde los inicios, un mayor número de mujeres. De acuerdo a las estadísticas oficiales de todo el país, el número de maestros egresados no dejó de crecer entre 1905 y 1964, al ritmo que iba aumentando la cantidad de mujeres año a año. En 1905 ellas representaban el 73 por ciento del total de maestros, pasaron a ser el $84.7 \%$ en 1932 y el $90 \%$ en 1964 (Lobato, 2007, p. 64). Esto se debió a varias causas, por un lado hubo discursos como el de Domingo F. Sarmiento que desde el Estado promovían su inserción como docentes en razón de sus "virtudes naturales" que asociaban el rol de maestra al de madre (Lionetti, 2007). Al mismo tiempo, Sarmiento y otros al tos funcionarios creían que las mujeres, al ser menos "ambiciosas", podrían recibir sueldos modestos ya que se suponía que sus ingresos resultaban siempre un "complemento" en el hogar. Gracias a ello, se abaratarían los costos del sistema público de enseñanza para el Estado.

En referencia a las 31 maestras, 14 figuraban como solteras, 16 casadas, una se presentaba sin esposo pero con un hijo; 19 habían nacido en La Plata, y en otras ciudades de la provincia de Buenos Aires: dos en Ranchos, y las demás en Pergamino, Dolores, Saladillo, San Nicolás, Olavarría, Zárate y Necochea; y tres eran nacidas en ciudades de otras provincias: Rosario, Concordia y Puerto Madryn. En el caso de las casadas, tres de ellas aparecían al lado de sus esposos en el Quién es Quién... y una se mostraba junto a su padre. La mayoría era egresada de la Escuela Normal [en adelante EN] No 1 "Mary O’Graham" de La Plata (19), otras provenían de las EN No 2 "Dardo Rocha” de La Plata (4); la EN de Pergamino (1) y el resto se había recibido de maestra en instituciones privadas: el Colegio Normal "Inmaculada" de La Plata (2), la EN Popular de Saladillo, y el Colegio Normal de Lomas de Zamora (de dos no hay datos). Habían egresado entre 1913 y 1958 y seis estaban jubiladas.

La EN No 1, donde se habían formado más de la mitad de las maestras, se hallaba en el centro de la ciudad de La Plata, se había inaugurado 1888 bajo la dirección de la maestra norteamericana Mary O’Graham, quien había sido contratada por iniciativa de Domingo F. Sarmiento. ${ }^{8}$ En sus inicios fue mixta y la inscripción inicial había alcanzado a 293 alumnos en los niveles de inicial, primario y medio. En 1890 el nivel medio se hizo solo de mujeres y en 1891 se graduaron las primeras ocho maestras. En 1915 se abrió el Profesorado en Ciencias y Letras que fue cerrado en 1930. De acuerdo a las estadísticas de los años de 1930, la EN No 1 de La 
Plata era una de las siete instituciones que recibía el mayor presupuesto del país, junto con tres EN ubicadas en Capital Federal, y las de Santiago del Estero, Corrientes y Catamarca (Rodríguez, 2018a). Para esa época se decía que la EN de La Plata había sabido "atraer a su lado lo mejor y más selecto de la sociedad platense" (Reyna Almandós, 1938, p. 165).

Si a las EN concurrían las jóvenes de las clases medias, es preciso poner en contexto cuál era el valor del sueldo de una maestra en comparación con los otros trabajos disponibles para las mujeres. A diferencia de las obreras o las empleadas administrativas, empleadas de escritorio (dactilógrafa, taquígrafa y secretaria), vendedoras o telefonistas (Queirolo, 2018), en la provincia de Buenos Aires, las maestras recibieron el mismo sueldo que los hombres desde fines del siglo XIX, es decir, no hubo después de ese momento, brecha salarial. Distintos educadores y pedagogos como Pablo Pizzurno o Leopoldo Lugones denunciaron en reiteradas oportunidades el escaso valor del salario en comparación con otras profesiones burocráticas como la militar. De modo reiterado, distintos actores hablaban de la formación de un "proletariado intelectual" por causa de los bajos sueldos. Cabe aclarar que en las provincias se cobraba menos y eran frecuentes los atrasos. Los educadores que se pronunciaban a favor de que se aumentaran los salarios, se manifestaban preocupados por la "feminización" de la docencia y argumentaban que esa era la única manera de atraer más varones al magisterio.

De todos modos, los sueldos del magisterio, para una mujer, resultaban más altos que los de otras trabajadoras. De acuerdo a la Ley de Presupuesto de 1919 de la provincia de Buenos Aires, un/a director/a y un/a maestro/a de una escuela de más de 300 alumnos cobraban 340 y 210 pesos por mes respectivamente, mientras que un/a director/a, vice director/a en escuelas de menos matrícula y maestro/as de primero a cuarto grado, recibían 190, 190 y 150 pesos por mes respectivamente. De acuerdo a un estudio especializado, en 1920 una taquígrafa- dactilógrafa (que eran las que mejor ganaban) recibía en promedio 140 pesos, mientras que una empleada doméstica podía ganar 50 pesos mensuales y una costurera unos 27 pesos mensuales (Queirolo, 2018). Es decir, si bien el sueldo era modesto - sobre todo para los varones, que tenían otras posibilidades laborales-, la docencia, dentro de las otras profesiones femeninas, resultó un modo relativamente seguro de subsistencia, ascenso social, de obtención de reconocimiento y de prestigio para las mujeres de todas las clases sociales. De manera creciente, las maestras permanecieron en el mercado laboral hasta jubilarse, ya que - si no había serios apremios económicos- podían optar por tener un solo turno (mañana o tarde) y hacer que la profesión resultase compatible con las tareas domésticas y/o el rol de madre y esposa, y, eventualmente, hacer otros estudios y/o involucrarse en otras actividades, y/o acceder a otros trabajos. En este sentido, la profesión docente otorgaba posibilidades - tener tiempo y dinero- que eran impensadas para otras, mientras que en paralelo, los negocios de moda las iban considerando cada vez más como consumidoras (Caldo, 2013). Ciertamente, esta realidad convivía con otras donde las aspirantes al magisterio no provenían de hogares de clase media y, una vez recibidas, debieron trabajar en dos escuelas para poder solventarse, lo que constriñó mucho su margen de acción.

Retomando la comparación con otras profesiones, se suele asociar a la maestra con la enfermera (Lobato, 2007; Cammarota, 2018) en el sentido que las dos se feminizaron - aunque en el magisterio nunca dejó de haber varones, mientras que en la segunda se prohibió el ingreso de hombres-; y estarían vinculadas al "don de cuidar", en tanto "labores que se derivaban de la extensión de las funciones domésticas y desde sus atribuciones como abnegación, sacrificio y servicio", al tiempo que "perdían peso los atributos profesionales asociados con una formación específica” (Lobato, 2007, p. 323). A pesar de estas similitudes, consideramos que ciertas fuentes como los Quién es Quién nos permiten identificar que las dos profesiones eran valoradas diferentes en relación al prestigio: en la edición de La Plata, como ya vimos, no existía la categoría de "enfermera".

A continuación, en los siguientes cinco apartados desarrollaremos las 31 autobiografías de maestras, separadas en grupos diferenciados por edad, titulación y experiencia laboral: a) las maestras de más edad; b) maestras y profesoras normalistas; c) maestras con otros trabajos; d) maestras y universitarias; y en el último apartado e) caracterizaremos a los maestros. 


\section{A) Las maestras de más edad}

Del conjunto de quienes fueron principalmente maestras de grado (12), se encontraban las de mayor edad, en general jubiladas, destacándose de sus carreras su participación en asociaciones e instituciones de distinto tipo. Ellas eran: Aida Cioppesoni de Abella; María Amanda Correbo de Amatrian; María Dolores Corro; Teresa Margarita Delorenzo; Emma Gasparini; Alice Rachou de Donella; Nerina Sciaini de Mendoza Zelis; Edith Josefina Martínez de Sandmeyer; María Ángela Ceballos de Sanguinetti; Dora Nélida Valdovinos; María del Carmen Pérez Rosique; y Alicia Baudin de Pérez Conte. De este grupo podemos observar que seis egresadas de la $\mathrm{EN} \mathrm{N}^{\circ} 1$ obtuvieron sus primeros cargos en otras localidades cercanas a La Plata, seis estaban jubiladas y cuatro lo habían hecho como directoras. Seis habían realizado otros estudios y las más jóvenes fueron las que lograron ascender en la carrera y llegaron a ser inspectoras (Cuadro 1).

\section{CUADRO 1}

\begin{tabular}{|c|c|c|c|}
\hline Apellido & $\begin{array}{l}\text { Institución y } \\
\text { año de egreso }\end{array}$ & $\begin{array}{l}\text { Ubicación de las escuelas donde } \\
\text { trabajó y cargos que ocupó }\end{array}$ & Otros estudios \\
\hline Abella & $\mathrm{EN} \mathrm{N}^{\circ} 1,1913$ & Lanús y La Plata, jubilada & \\
\hline Corro & $\begin{array}{l}\text { EN Popular de } \\
\text { Saladillo, } 1918\end{array}$ & $\begin{array}{l}\text { Saladillo, Lanús y La Plata, jubilada } \\
\text { en } 1945\end{array}$ & \\
\hline Gasparini & $\begin{array}{l}\text { EN de Olavarría, } \\
\mathrm{s} / \mathrm{d}\end{array}$ & $\begin{array}{l}\text { Wilde y en Avellaneda, donde llegó } \\
\text { a ser directora, jubilada en } 1942\end{array}$ & \\
\hline Donella & $\mathrm{EN} \mathrm{N}^{\circ} 1,1919$ & $\begin{array}{l}\text { General Pinto, Ranchos y Berisso, } \\
\text { jubilada en } 1941\end{array}$ & $\begin{array}{l}\text { Profesora de francés } \\
\text { (Alianza Francesa, 1928) }\end{array}$ \\
\hline Sanguinetti & $\mathrm{EN} \mathrm{N}^{\circ} 1, \mathrm{~s} / \mathrm{d}$ & $\begin{array}{l}\text { Lomas de Zamora y Berisso, donde } \\
\text { fue directora en La Plata, jubilada en } \\
1942\end{array}$ & \\
\hline Delorenzo & $\mathrm{EN} \mathrm{N}^{\circ} 1,1921$ & $\begin{array}{l}\text { Avellaneda, Lanús y directora en } \mathrm{La} \\
\text { Plata, jubilada en } 1950\end{array}$ & \\
\hline $\begin{array}{l}\text { Mendoza } \\
\text { Zelis }\end{array}$ & $\mathrm{EN} \mathrm{N}^{\circ} 1,1936$ & $\begin{array}{l}\text { Berisso y fue directora en una } \\
\text { escuela de las afueras de La Plata }\end{array}$ & \\
\hline Valdovinos & $\mathrm{EN} \mathrm{N}^{\circ} 1,1936$ & $\begin{array}{l}\text { Maestra, maestra de enseñanza } \\
\text { diferenciada, maestra especial de } \\
\text { música y de danzas tradicionales }\end{array}$ & $\begin{array}{l}\text { Escuela de Danzas } \\
\text { Tradicionales (1954) }\end{array}$ \\
\hline $\begin{array}{l}\text { Pérez } \\
\text { Rosique }\end{array}$ & $\mathrm{s} / \mathrm{d}, 1941$ & $\begin{array}{l}\text { Directora (1945) e inspectora de } \\
\text { psicología }\end{array}$ & Auxiliar de psiquiatría \\
\hline Pérez Conte & $\mathrm{EN} \mathrm{N}^{\circ} 1,1944$ & $\begin{array}{l}\text { La Plata, vice directora en Berisso e } \\
\text { inspectora de enseñanza primaria }\end{array}$ & $\begin{array}{l}\text { Auxiliar técnico en } \\
\text { educación sanitaria }(1960)\end{array}$ \\
\hline Amatrian & $\mathrm{EN} \mathrm{N}^{\circ} 2,1947$ & $\begin{array}{l}\text { Quilmes, Ensenada y La Plata. } \\
\text { Ejerció como maestra de educación } \\
\text { diferenciada }\end{array}$ & Asistente educacional \\
\hline Sandmeyer & $\mathrm{s} / \mathrm{d}$ & Maestra y bibliotecaria & $\begin{array}{lrr}\text { Hizo estudios de } \\
\text { conservación de documentos }\end{array}$ \\
\hline
\end{tabular}

En estas biografías, las maestras destacaban además los otros trabajos que tenían y las asociaciones e instituciones en las que participaban: Abella era secretaria de la Liga de Amas de Casa (1967-1971), miembro de la Sociedad Protectora de la Niñez, del Asilo Maternal, presidenta del Instituto del Tórax, contribuía con la cooperadora del Asilo Marín y del Hogar Santa María de Sordomudos. Su actividad gremial estaba concentrada en la Asociación de Maestros. Corro también integraba la comisión directiva de la Asociación de Maestros, dirigía la revista y el boletín; había sido co fundadora de la Universidad Popular "Alejandro Korn" y estuvo en la secretaría del Colegio Libre de Estudios Superiores. Esta maestra además hizo una carrera en la administración pública: ingresó en 1956 a la Dirección de Menores de la provincia y entre 1958 y 1959 fue subdirectora general. Donella participaba activamente de la Asociación de Maestros y asumió como secretaria 
del Consejo Escolar y fue su presidenta (1960-1966). Gasparini, después de jubilada, siguió como regente de una institución privada católica de formación docente de La Plata, recibiendo homenajes en vida, siendo nombrada madrina de una escuela secundaria. Sanguinetti integraba la comisión directiva del Patronato de Leprosos y era la presidenta desde 1964; y Delorenzo era la tesorera de la misma institución desde 1954. Mendoza Zelis era bibliotecaria del Instituto Superior de Relaciones Humanas del Ministerio de Educación y daba clases de danzas folklóricas y de arte floral en una escuela de formación profesional; Amatrian colaboraba con la Liga Popular de Lucha contra el Cáncer; Sandmeyer resultó presidenta del Colegio de Bibliotecarios, jefa del departamento de la Biblioteca Central del Ministerio de Bienestar Social y bibliotecaria del Colegio de Abogados; y Valdovinos fue cofundadora y secretaria de la ex agrupación tradicionalista "Aspha Sumaj", articulista en diarios locales, co fundadora femenina, integrante y solista del Coro Universitario, autora de poemas y de un libro sobre teatro escolar, obteniendo distinciones como escritora, por una pieza de teatro y sus poemas. Pérez Rosique era asistente educacional de la Dirección de Psicología de la provincia y delegada de la Parroquia San Roque, presidenta de la Congregación Hijas de María y presidenta de la Asociación de Mujeres de Acción Católica (AMAC); y Pérez Conte participaba activamente de encuentros, jornadas y congresos pedagógicos.

\section{B) Maestras y profesoras normalistas}

Cinco de las maestras habían realizado estudios de Profesorado en las EN: Margarita Albertella; Amanda del Frate Ayarza de Lockhart; María Luisa Madueño; Josefina Amelia Pessaq; y María Adela West Ocampo. Tres de ellas eran egresadas del Profesorado de Letras que funcionó en la EN No 1 entre 1915 y 1930 (Cuadro 2). Desde los inicios de la creación de la carrera de magisterio, algunas EN ofrecían a sus estudiantes la posibilidad de seguir el Profesorado, que en general eran dos o tres años más de estudios, en las orientaciones de Letras o Ciencias (con el tiempo se fueron diversificando las titulaciones). De acuerdo a un pedagogo que escribía en los años de 1960, "la maestra joven de hacía treinta o cuarenta años atrás... comenzaba su carrera pensando que había llegado al más alto grado de las aspiraciones intelectuales o económicas de una mujer. Las más inteligentes y capaces, las muy ambiciosas y esforzadas seguían, a lo sumo, un Profesorado" (Zanotti, 1960). Más allá de lo que se esperara de las mujeres en los años de 1920 y 1930, de acuerdo a la normativa, este otro título representaba una importante oportunidad laboral, porque las habilitaba, tanto a ser maestras de primaria, como a aspirar a cargos de inspectoras, directoras o profesoras de enseñanza media en cualquier EN. La diferencia era importante a nivel salarial: si una maestra en una escuela provincial podía ganar 210 \$, en 1913 una profesora con tres cátedras de Ciencias o Letras en una EN nacional llegaba a recibir 540 \$ por mes. Sin embargo, como se podrá apreciar en el Cuadro, casi todas llegaron a ser sólo directoras de primaria en la provincia o profesoras en institutos - no en EN-. Solo una docente - de las 31- fue profesora y vice directora en la EN No 1 de La Plata (West Ocampo). 


\section{CUADRO 2}

\begin{tabular}{|c|c|c|c|}
\hline Apellido & $\begin{array}{l}\text { Institución } \\
\text { y año de } \\
\text { egreso }\end{array}$ & $\begin{array}{l}\text { Ubicación de las escuelas donde } \\
\text { trabajó. Cargos que ocupó }\end{array}$ & Otros estudios \\
\hline Pessaq & $\begin{array}{l}\mathrm{EN} \\
\mathrm{s} / \mathrm{d}\end{array}$ & $\begin{array}{l}\text { Maestra en La Plata y directora en } \\
\text { Berisso }\end{array}$ & $\begin{array}{l}\left.\text { Profesora Normal de Letras (EN N }{ }^{\circ} 1\right) \\
\text { Profesora de francés (Alianza Francesa) }\end{array}$ \\
\hline West Ocampo & $\begin{array}{l}\text { EN No 1, } \\
1917\end{array}$ & $\begin{array}{l}\text { Directora escuela primaria de Junín, } \\
\text { regente de la EN Popular de Junín. } \\
\text { Colaboró con las Hermanas de la } \\
\text { Cruz para fundar una EN privada, } \\
\text { de la que luego fue regente. Fue } \\
\text { profesora de castellano y religión en } \\
\text { la EN N } N^{\circ}(1943) \text {. Vicedirectora de } \\
\text { la } E^{\circ} N^{\circ}(1957-63)\end{array}$ & Profesora Normal de Letras (EN No 1$)$ \\
\hline Lockhart & $\begin{array}{l}\mathrm{EN} \mathrm{N}_{1929} \mathrm{~N}^{\circ} 1 \text {, } \\
\end{array}$ & $\mathrm{s} / \mathrm{d}$ & Profesora Normal de Letras $\left(\mathrm{EN} \mathrm{N}^{\circ} 1\right)$ \\
\hline Albertella & $\begin{array}{l}\text { EN No 1, } \\
\mathrm{s} / \mathrm{d}\end{array}$ & $\begin{array}{l}\text { Maestra jardinera y directora de } \\
\text { Jardín de Infantes de La Plata. } \\
\text { Profesora de Educación Fisica }\end{array}$ & $\begin{array}{l}\text { Profesora Normal de la ex EN de } \\
\text { Educación Física de la provincia de } \\
\text { Buenos Aires }\end{array}$ \\
\hline Madueño & $\begin{array}{l}\text { Colegio } \\
\text { Normal } \\
\text { Inmaculada } \\
\text { de La Plata, } \\
\mathrm{s} / \mathrm{d}\end{array}$ & $\begin{array}{l}\text { Maestra y directora de primaria. } \\
\text { Profesora en institutos de nivel } \\
\text { secundario y superior de Tandil, } \mathrm{La} \\
\text { Plata y Bariloche }\end{array}$ & $\begin{array}{l}\text { Profesora Normal de Jardín de Infantes } \\
\text { de la EN No } 1 \text {. } \\
\text { Profesora de Estética, Mímica y Música } \\
\text { egresada del Instituto Docente de } \\
\text { Educación Estética Infantil }\end{array}$ \\
\hline
\end{tabular}

Igual que en los otros casos, estas maestras exhibían en sus biografías otros datos que ellas creían relevantes: Lockhart no hacía referencia a su trayectoria como maestra y solo destacaba su actuación dentro de la Biblioteca Musical Verdi desde los años de 1930 en la comisión directiva, como vicepresidenta y presidenta (1970-72). West Ocampo decía pertenecer a la Acción Católica de Junín y luego de La Plata, presidiendo durante tres años (1953-56) el Consejo Arquidiocesano de las Mujeres de la Acción Católica. Pessaq tenía una trayectoria gremial importante en la Asociación de Maestros donde asumió como presidenta y en 1956 fue una de las pocas mujeres que fue nombrada vocal del Consejo Nacional de Educación, aunque solo permaneció unos meses. Albertella hizo cursos, dictó conferencias, asistió a congresos, era autora de artículos sobre educación, había integrado la Asociación por los Derechos del Niño y el Colegio Libre de Estudios Superiores. En ese momento era miembro de la Asociación de ex alumnas de la EN No 1 y de la Organización Mundial para la Educación Preescolar. Madueño se especializó en teatro de títeres, siendo directora del Teatro de Títeres "El Retablo". Ocupó cargos de asesora en el área de Teatro en el Departamento de Educación del Ministerio de Bienestar Social y tuvo a su cargo el aspecto recreativo en el Departamento de Extensión Universitaria de la UNLP. Participó de numerosos congresos, festivales de títeres, dio conferencias en el país y en el exterior, escribió libros de su especialidad y recibió distinciones y premios.

\section{C) Maestras con otros trabajos}

Un tercer conjunto de siete maestras, en general más jóvenes, no aportaban información sobre las escuelas donde habían dado clases (excepto Madalin) y destacaban los otros trabajos que habían desempeñado (Cuadro 3): Ana Emilia Lahitte; María Elida Alvarez de Caggiano; María Teresa Villafañe Casal; Ligia Mercader de Argüello; Lilian (Buyi) Pullán de Presas; Marta Susana Keilis de Madalin; y Marta Albanese. 
CUADRO 3

\begin{tabular}{|c|c|c|c|}
\hline Apellido & $\begin{array}{l}\text { Institución y } \\
\text { año de egreso }\end{array}$ & Otros estudios & Actividades laborales \\
\hline Lahitte & $\begin{array}{lll}\mathrm{EN} & \mathrm{N}^{\circ} & 1 \\
1939 & & \end{array}$ & & $\begin{array}{l}\text { Secretaria del Departamento de Teatro de la } \\
\text { UNLP y secretaria de la SADE. Asistente } \\
\text { técnica de la Subsecretaría de Cultura } \\
\text { Escritora de poesía, cuentos, ensayo, teatro, } \\
\text { literatura infantil y periodismo }\end{array}$ \\
\hline Caggiano & $\mathrm{EN} \mathrm{N}^{\circ} 1, \mathrm{~s} / \mathrm{d}$ & $\begin{array}{l}\text { Diploma de Visitadora de } \\
\text { Higiene Social } \\
\text { Profesora de piano }\end{array}$ & $\begin{array}{l}\text { Maestra hasta } 1945 \text { que renunció. Concentró } \\
\text { toda su actividad posterior en torno a la } \\
\text { política afiliándose a la UCR y UCR del Pueblo }\end{array}$ \\
\hline Villafañe Casal & $\begin{array}{l}\text { Colegio } \\
\text { Normal de } \\
\text { Lomas de } \\
\text { Zamora, s/d }\end{array}$ & & $\begin{array}{l}\text { Ejerció principalmente como profesora de } \\
\text { historia y geografia. Fue directora del Instituto } \\
\text { de la Tradición y jefa del Departamento de } \\
\text { Estudios Folklóricos y Etnográficos del } \\
\text { Ministerio de Educación. Profesora de la } \\
\text { UNLP. Secretaria general del Instituto de } \\
\text { Folklore de Historia Bonaerense }\end{array}$ \\
\hline Argüello & $\begin{array}{lll}\mathrm{EN} & \mathrm{N}^{\circ} \quad 1, \\
1945 & & \end{array}$ & $\begin{array}{l}\text { Curso de Psicopedagogía (1946) } \\
\text { Curso de Ciencias } \\
\text { Administrativas UNLP (1958) }\end{array}$ & $\begin{array}{l}\text { Empleada administrativa en distintas } \\
\text { dependencias de la UNLP desde } 1952\end{array}$ \\
\hline Presas & $\begin{array}{l}\text { Escuela } \\
\text { Normal Mixta } \\
\text { de Pergamino, } \\
1957\end{array}$ & $\begin{array}{l}\text { Cursos de dibujo publicitario } \\
\text { Carrera incompleta de Dibujo y } \\
\text { Pintura (UNLP) } \\
\text { Cursos en Alemania (1963-66) }\end{array}$ & $\begin{array}{l}\text { Docente particular de talleres de cerámica } \\
\text { Tlustradora de libros }\end{array}$ \\
\hline Madalin & $\begin{array}{l}\text { Colegio } \\
\text { Normal } \\
\text { Inmaculada, } \\
1958\end{array}$ & $\begin{array}{l}\text { Escuela de Servicio Social del } \\
\text { Ministerio de Bienestar Social } \\
(1964)\end{array}$ & $\begin{array}{l}\text { Maestra en escuelas privadas católicas de La } \\
\text { Plata donde fue directora en } 1960 \text {. En escuelas } \\
\text { públicas de las afueras de } \mathrm{La} \text { Plata dio clases a } \\
\text { niños con aprendizaje lento. En } 1968 \text { renunció } \\
\text { a sus cargos de maestra y se dedicó a } \\
\text { conformar gabinetes de psicología y asistente } \\
\text { educacional en las escuelas primarias, siendo } \\
\text { asesora del Servicio Social de la provincia en } \\
1970\end{array}$ \\
\hline Albanese & $\begin{array}{lll}\mathrm{EN} & \mathrm{N}^{\circ} 2, \\
1958 & \end{array}$ & $\begin{array}{l}\text { Conservatorio de Arte Escénico } \\
\text { (1962) }\end{array}$ & $\begin{array}{l}\text { Actriz de numerosas obras de teatro, } \\
\text { televisión, radio y cine }\end{array}$ \\
\hline
\end{tabular}

En relación a sus otras actividades, Lahitte era integrante y secretaria de la SADE, miembro del PEN (Poetas, Ensayistas y Narradores) Club en la Argentina, del Círculo de Periodistas, de la Asociación de Periodistas y Escritores de Turismo y desde 1970 presidente de la Asociación Mundial de Mujeres Periodistas y Escritoras en la Argentina. Había recibido una beca de la OEA (1966) y del Instituto de Cultura Hispánica de Madrid y numerosas distinciones y premios por sus ensayos, poesías y sus notas sobre turismo cultural. Villafañe Casal dio numerosas conferencias, escribió varios libros, y recibió premios y becas - una del Fondo Nacional de las Artes- por sus investigaciones sobre etnografía, arqueología, historia y folklore. Caggiano se diferenciaba del conjunto de las 31 maestras porque exhibía una importante trayectoria como dirigente política de la Unión Cívica Radical (UCR) y luego de la UCR del Pueblo: había ejercido como maestra hasta que en 1945 renunció y se dedicó a ocupar cargos partidarios y ser candidata, convirtiéndose en la primera mujer del radicalismo que integró la Junta Central de La Plata. Era además integrante de la Biblioteca Musical Verdi y secretaria general de la Liga Popular de Lucha Contra el Cáncer. En virtud de esta última vinculación, intervino en audiciones radiales y televisivas y en congresos específicos. Cuatro de las más jóvenes: Argüello, Presas, Madalin y Albanese omitían mencionar si realizaban otras actividades. 


\section{D) Maestras y universitarias}

Los especialistas coinciden en que hacia los años de 1940 se inició el proceso de masificación de la escuela secundaria y en particular, del ingreso de las mujeres al nivel medio y que esto repercutió a su vez en la matrícula universitaria. Si bien había egresadas universitarias desde el siglo XIX, la expansión de la matrícula femenina hizo que hacia las décadas de 1950 y 1960 el número de alumnas y egresadas en las universidades creciera exponencialmente (Lobato, 2007). La titulación femenina en las universidades nacionales pasó de 0,8 $\%$ (1900-1905) al 10,3\% (1931-1935), superando el $21 \%$ en 1951-1955 y llegando al 29,2 \% en 1961-1965 (Lobato, 2007, p. 65).

En referencia a los normalistas, en el año 1941 el llamado "Plan Rothe" los habilitó por primera vez a aspirar a la universidad, hecho que solo les estaba permitido a los egresados de los Colegios Nacionales y de los Liceos de Señoritas, si aprobaban el examen de ingreso. Antes de ese año, los normalistas que querían ingresar a la universidad debían rendir materias libres para obtener primero el título de bachilleres, como en el caso de las primeras médicas Cecilia Grierson y Elvira Rawson. De todos modos, en la UBA, las autoridades de la Facultad de Filosofía y Letras aceptaron desde los inicios a normalistas en sus profesorados. En la UNLP, Susana García (2006) ha mostrado que desde su fundación, los egresados normalistas fueron admitidos en todos los profesorados de la Facultad de Humanidades y Ciencias de la Educación, en las carreras de la Facultad de Ciencias Químicas y Farmacia, de la Escuela Superior de Bellas Artes (profesorados) y del Instituto del Museo. Esto explicaría en parte que esas instituciones presentaran una considerable proporción femenina de egresados hacia las décadas de 1920 y 1930 (Arias, 2017).

La posibilidad que se abrió en 1941 fue vista negativamente por ciertos especialistas. Como decía en tono crítico un pedagogo en 1960, si bien las mujeres seguían concurriendo a las Escuelas Normales, la gran mayoría de las alumnas deseaba en realidad "seguir carreras universitarias que casi nunca tenían que ver con la enseñanza”. La maestra suplente, se quejaba, iba a dar clases a la escuela primaria "con los libros de la Facultad de Medicina, Abogacía o Arquitectura bajo el brazo, no se podía quedar a la reunión de personal convocada por la directora porque debía llegar a una clase de trabajos prácticos o asistir a una conferencia" (Zanotti, 1960).

Seis de las más jóvenes se habían recibido en la UNLP entre las décadas de 1940 y 1960 - a excepción de Vidal Loza, egresada en los años de 1930-y seis habían hecho profesorados: Elba Teresa Cepeda de Vidal Loza; Lía Esther Anselmino de Tortonese; Lucrecia Silva Noseda; Martha Mercader; Aurora Raquel Groizard; María Laura Kienzelman de De Ponti; y María Esther Girotto. Cuatro de estas maestras y universitarias no hacía ninguna mención a su desempeño en el nivel primario y se presentaban como profesoras de nivel medio y universitario (Cuadro 4). 
CUADRO 4

\begin{tabular}{|c|c|c|c|}
\hline Apellido & $\begin{array}{c}\text { Institución } \\
\text { y año de } \\
\text { egreso }\end{array}$ & Estudios en la UNLP & Actividades laborales \\
\hline Vidal Loza & $\begin{array}{l}\mathrm{EN} \mathrm{N}^{\circ} 1, \\
1926\end{array}$ & 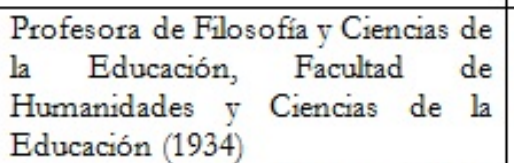 & $\begin{array}{l}\text { Maestra en La Plata }\left(E N N^{\circ} \text { 1) y }\right. \\
\text { directora fundadora del jardín de } \\
\text { infantes de la } \mathrm{EN} \mathrm{N}^{\circ} 2\end{array}$ \\
\hline Tortonese & $\begin{array}{l}\mathrm{EN} \mathrm{N}^{\circ} 1 \\
1937\end{array}$ & \begin{tabular}{llcc|} 
Profesora de & Piano & $(1942)$. \\
Profesora de Música & $(1944)$, \\
Escuela Superior de Bellas Artes
\end{tabular} & $\begin{array}{l}\text { Maestra en La Plata (1937-46) profesora } \\
\text { de música de nivel medio en distintas } \\
\text { EN (1946-67). Inspectora de educación } \\
\text { musical y asesora (1949-67). } \\
\text { Interventora Escuela de Danzas (1966- } \\
\text { 68). Directora del Teatro Argentino } \\
\text { (1966-1968). Jubilada (1968) }\end{array}$ \\
\hline Silva Noseda & $\begin{array}{l}\mathrm{EN} \mathrm{N}^{\circ} 1 \\
1938\end{array}$ & $\begin{array}{l}\text { Profesora de Filosofía, Facultad de } \\
\text { Humanidades y Ciencias de la } \\
\text { Educación (1951) }\end{array}$ & $\begin{array}{l}\text { Profesora en colegios secundarios } \\
(1956-71)\end{array}$ \\
\hline Mercader & $\begin{array}{l}\mathrm{EN} \mathrm{N} \mathrm{N}^{\circ} 1, \\
1943\end{array}$ & $\begin{array}{l}\text { Profesora de Inglés } \quad \text { (1948) } \\
\text { Traductora Pública } \\
\text { de Humanidades y } \\
\text { Educaciencias de la la } \\
\text { Educalon }\end{array}$ & $\begin{array}{l}\text { Profesora en colegios secundarios, en } \\
\text { el Instituto Cultural Argentino-Británico } \\
\text { y la Asociación Argentina de Cultura } \\
\text { Inglesa. Profesora en la UNLP (1949- } \\
\text { 54). Traductora OEA (1957-59). } \\
\text { UNESCO (1961-62). Directora de } \\
\text { Cultura (1963-66). Directora de de } \\
\text { Enseñanza Artística (1964). Trabajó } \\
\text { como periodista en revistas, televisión y } \\
\text { radio. Tradujo numerosas obras. }\end{array}$ \\
\hline Groizard & $\begin{array}{l}\mathrm{EN} \mathrm{N} \mathrm{N}^{\circ} 2, \\
1946\end{array}$ & $\begin{array}{llll}\text { Profesora de } & \text { Dibujo, Escuela } \\
\text { Superior de Bellas } & \text { Artes (1954) } & \\
\text { Bibliotecaria, } & \text { Facultad } & \text { de } \\
\text { Humanidades y } & \text { Ciencias de la } \\
\text { Educación (1962) } & & & \end{array}$ & $\begin{array}{l}\text { Desde } 1954 \text { hasta el presente, ejerce } \\
\text { como maestra especial de expresión en } \\
\text { el nivel primario. Profesora en el nivel } \\
\text { secundario y terciario. }\end{array}$ \\
\hline De Ponti & $\begin{array}{l}\mathrm{EN} \mathrm{N} \mathrm{N}^{\circ} 1, \\
1950\end{array}$ & $\begin{array}{l}\text { Profesora de Inglés, Facultad de } \\
\text { Humanidades y Ciencias de la } \\
\text { Educación (1955) } \\
\text { Cursos para post graduados de su } \\
\text { especialidad }\end{array}$ & $\begin{array}{l}\text { Profesora de inglés en colegios } \\
\text { secundarios y primarios de la UNLP. } \\
\text { Trabajos de Traductora. }\end{array}$ \\
\hline Girotto & $\begin{array}{l}\text { EN } \\
\text { s/d }\end{array}$ & $\begin{array}{llll}\text { Periodista, } & \text { Escuela } & \text { Superior de } \\
\text { Periodismo (1971) } & & \end{array}$ & $\begin{array}{l}\text { Redactora Boletín UNLP (1958). } \\
\text { Periodista en diarios, revistas y radios. } \\
\text { Personal administrativo de la UNLP } \\
\text { desde 1965. Profesora en la UNLP }\end{array}$ \\
\hline
\end{tabular}

Vidal Loza agregaba a su biografía que era miembro del directorio de la Sociedad Agropecuaria "Arturo Cepeda" (1960); Tortonese sumaba el haber sido asesora musical de la Biblioteca Verdi hasta su jubilación en 1968, presidir la subcomisión de música del Jockey Club provincial, y haber dictado cursos y conferencias, escrito y traducido artículos relativos a su especialidad, y participado en audiciones radicales y televisivas sobre educación musical. Silva Noseda añadía que era autora de varios poemas publicados en diarios y revistas; Groizard decía haber participado en Congresos de Bibliotecología y ser miembro consejero de la Asociación Argentina Pro Naciones Unidas desde 1962. Mercader se destacaba del grupo de 31 maestras, en tanto fue la que alcanzó a tener una mayor proyección nacional: hacia 1972 era conocida por su participación en distintos medios de comunicación de la Capital Federal, había publicado sus primeras obras, viajado a Europa en varias oportunidades y había recibido importantes distinciones. ${ }^{9}$ De Ponti y Girotto no incluían nada más a sus trayectorias. 


\section{E) Los maestros: la segregación vertical}

$\mathrm{Al}$ igual que en otras profesiones, las maestras sufrieron la segregación vertical al tener menos oportunidades de ascender en la carrera docente que los varones, quienes a los pocos años de estar frente al aula podían ser nombrados directores de las escuelas, profesores en el nivel secundario, inspectores o funcionarios políticos. Un estudio ubicado en el Territorio Nacional de La Pampa de María José Billorou (2015) muestra cómo las autoridades valoraban de manera distinta las carreras de los maestros y maestras: para los varones, los años de antigüedad no fueron considerados un factor de peso, así como tampoco les exigieron para su promoción que fuesen ocupando todas las categorías en orden y progresivamente (Billorou, 2015). La investigadora ilustra que un maestro con doce años en la tercera categoría fue designado director de una escuela primaria de primera categoría, mientras que una maestra con más de veinte años de servicio en la misma escuela fue promovida a maestra de primera categoría; y dos maestras recibieron la promoción a la segunda categoría luego de más de quince años en la tercera. Asimismo, las escuelas rurales de personal único, aisladas, y con gran exigencia de trabajo, tanto pedagógico como administrativo, se convirtieron en destino de una gran cantidad de maestras, quienes permanecían en ese tipo de cargos mucho más tiempo que los varones (Billorou, 2015).

Del grupo de cinco hombres -Juan Martín Ametrano, Rodolfo Pérez Duprat, Osvaldo Domingo Tomatti, Lope Torres y José María "Coya" Mercado- figuraban tres como "maestros normales nacionales", uno como "educador" y otro como "maestro normal regional" ${ }^{10}$ Habían nacido en otras ciudades de la provincia de Buenos Aires (Las Flores, Magdalena y Ranchos), uno era extranjero nacionalizado (Uruguay) y otro provenía de una provincia del norte (Jujuy). Sólo dos explicitaban de qué institución eran egresados (EN de Las Flores y EN Regional de Humahuaca) y el resto omitía ese dato. En relación a sus auto biografías, Ametrano se presentaba como concejal, intendente, subsecretario de educación y ministro. Muy ligado a la educación privada y católica, se mantenía en la gestión como presidente del Consejo para la Equiparación de Docentes no Oficiales. Pérez Duprat llegó a ser inspector y también director general de educación interino (ministro). Se desempeñó como director de escuelas que dependían de la Universidad, publicó numerosos libros, era de la Asociación de Maestros y de la SADE. Tomatti se dedicó al periodismo y se especializó en deportes, viajando en varias oportunidades a Europa a cubrir eventos. También era de la Asociación de Maestros y del Rotary Club. Torres fue inspector, presidente del Consejo Escolar, autor de libros de lectura, concejal, y decía haber contribuido a fundar el Club Atenas. Mercado ejerció como maestro en Jujuy y en La Plata, al tiempo que daba conciertos como guitarrista, ayudó a fundar la Universidad Popular de Abra Pampa, dio numerosas conferencias e integraba la Peña Pacaría que funcionaba en la Universidad Popular Alborada. A diferencia de las mujeres, estas y otras biografías de los hombres que aparecían en el Quién es Quién..., se caracterizaban por pertenecer a diversas instituciones y organizaciones deportivas y de juego (de Ajedrecistas, Club Automovilista, Los Tilos, Hípico, de fútbol: Gimnasia y Estudiantes, entre otras) y asociaciones como el Jockey Club o la Filatelista, además de tener una inserción en las asociaciones profesionales como los Colegios.

\section{REFleXiones FinAles}

En este artículo realizamos un análisis de 31 autobiografías de mujeres que aparecían en el Quién es Quién en La Plata, que eran consideradas por sus contemporáneos como parte de la élite intelectual y profesional de la ciudad, en razón de su título de maestras normales, su pertenencia de clase y sus trayectorias. Al contrario de una maestra que debía trabajar en dos escuelas de mañana y de tarde, se diferenciaban de las otras docentes por tener la posibilidad de trabajar en un solo turno o no ejercer de maestras, lo que les permitió emplear su tiempo libre y sus recursos para realizar otros estudios, acceder a otros trabajos y/o realizar distintas actividades. 
Hemos visto que sus trayectorias estuvieron marcadas por el año en que se recibieron, los tipos de estudios, trabajos y actividades que hicieron, y las posibilidades de ascender a los puestos jerárquicos. Sobre la primera cuestión, señalamos que las maestras de más edad, recibidas entre las décadas de 1910 y 1940, se dedicaron en buena medida a la docencia en el nivel primario y las más jóvenes, egresadas en su mayoría después de 1940, ocuparon otros trabajos, hicieron la universidad y ejercieron la docencia en el nivel medio y universitario. Estas situaciones nos ilustran el cambio social y las transformaciones que se fueron dando en la sociedad argentina que afectaron no solo a las maestras, sino de manera similar a otras generaciones de mujeres. En relación a los otros estudios y trabajos que realizaron, estos estuvieron vinculados a la enseñanza (filosofía, historia, geografía, ciencias de la educación, letras, educación física y jardín de infantes; de disciplinas artísticas como música, cerámica, teatro y dibujo; e idiomas, principalmente inglés y francés); al cuidado (asistentes sociales, auxiliares de psiquiatría, psicología, higiene y sanidad); y al servicio (administrativas y bibliotecarias). Además de docentes, siete de ellas mencionaban ser escritoras, novelistas, poetas y periodistas especializadas en teatro, cultura, etnografía, folklore e historia, y habían sido merecedoras de premios, becas y distinciones, destacándose una de ellas, que logró que su obra alcanzara proyección nacional. Se diferenciaban de este grupo una maestra que abandonó la docencia para dedicarse a la militancia dentro de un partido político; y una actriz.

Casi todas las maestras colaboraban en organizaciones de ayuda social: Patronato de Leprosos (2), Liga Popular de Lucha contra el Cáncer (2), Liga de Amas de Casa, Sociedad Protectora de la Niñez, Asociación por los Derechos del Niño, Asilo Maternal, Instituto del Tórax, Asilo Marín, Hogar de Sordomudos, Acción Católica, Parroquia San Roque, Congregación Hijas de María y Asociación de Mujeres de Acción Católica (AMAC). Otras estaban vinculadas a instituciones relacionadas con las letras, las artes y la enseñanza, como la SADE, el PEN, Biblioteca Musical Verdi (2), subcomisión de música del Jockey Club, Asociación Argentina Pro Naciones Unidas, Sociedad Agropecuaria “Arturo Cepeda”, Universidad Popular “Alejandro Korn” y Colegio Libre de Estudios Superiores (2). Cuatro de las maestras de más edad habían tenido actividad en el gremio de la Asociación de Maestros y una había sido presidenta del Consejo Escolar. Solo cinco de las más jóvenes omitían cualquier referencia a sus actividades por fuera del ámbito laboral.

Por último, observamos que aún cuando eran mujeres reconocidas y valoradas, la mayoría no logró ascender en la carrera - por lo menos hasta 1972- : de las 22 que decían haber trabajado como maestras en primaria, solo una, recibida de profesora normal, resultó profesora y vice directora en la EN de La Plata; mientras que nueve alcanzaron a ser directoras de escuelas provinciales - tres recibidas además de profesoras normales- $\mathrm{y}$ tres inspectoras (de la cuales una había sido directora). De las que trabajaron en el nivel medio y la universidad, ninguna llegó a ser directora, inspectora, jefa de departamento o decana. Solo dos ocuparon altos cargos como funcionarias del área educativa durante unos meses: una en el Consejo Nacional de Educación y otra como directora de enseñanza artística. En contraste, los cinco maestros varones, que no tenían otra titulación, fueron ministros, inspectores y uno, director de un colegio de nivel secundario de la Universidad.

Ahora bien, consideramos que resulta relevante continuar realizando este tipo de estudios - basados en los Quién es Quién o en otras fuentes- de biografías colectivas de distintas generaciones en otras ciudades del país, para poder identificar las semejanzas y diferencias con otros grupos de maestras, con el propósito de adquirir una mirada más diversa y compleja de las egresadas de las Escuelas Normales en la Argentina.

\section{REFERENCIAS}

Alvarado, M. (2016). "El Alegato de Florencia Fossatti: claves para una historia de las ideas pedagógicas desde una epistemología feminista”. Historia de la educación. Anuario, 17, (2), pp. 104-119.

Alliaud, A. (2007). Los maestros y su historia. Los origenes del magisterio argentino. Granica: Buenos Aires. 
Arias, A. C. (2017). Mujeres universitarias en la Argentina. Algunas cuestiones acerca de la Universidad Nacional de La Plata en las primeras décadas del siglo XX. Trabajo final de la Especialización en Educación en géneros y sexualidades. La Plata: Facultad de Humanidades y Ciencias de la Educación, UNLP.

Barrancos, D. (2008). “Maestras, librepensadoras y feministas en la Argentina (1900-1912)”. En Altamirano, C. (Dir.). Historia de los intelectuales en América Latina, tomo I. Buenos Aires: Katz, pp. $465-494$

Becerra, M. (2016). "Un prisma original: educación, género, amor y ciudadanía en Herminia Brumana”. Historia de la educación. Anuario, 17, (2), pp. 80-103.

Becerra, M (2020). "Soy comunista y maestra: resistencias a la maternalización de las mujeres a través de la obra de Angélica Mendoza en la Argentina de los años '20 y '30”. Izquierdas, 49, pp. 385-411.

Billorou, M. J. (2015). "Mujeres que trabajan. Las maestras pampeanas en la primera mitad del siglo XX”. Anuario. Facultad de Ciencias Humanas, 12, (2), pp. 1-18.

Bourdieu, P. (2000). La dominación masculina. Barcelona: Anagrama.

Caldo, P. (2013). "El hábito hace a la maestra. Hacia una historia de las prácticas de consumo de las mujeres dedicadas a la docencia en Argentina, 1939-1943”. Naveg@mérica. Revista electrónica de la Asociación Española de Americanistas, (10). Recuperada de http://revistas.um.es/navegamerica.

Caldo, P. (2018). "Tizas y Apuntes: costumbres en común. Maestras, libros y prácticas de enseñanza en la Argentina de 1930”. En F. Fiorucci y L. G. Rodríguez (comp.). Intelectuales de la educación y el Estado: maestros, médicos y arquitectos. Bernal: Universidad Nacional de Quilmes, pp. 115-140

Cammarota, A. (2018). "Entre maestras y enfermeras. La construcción del género y de un ethos particular en torno a la enseñanza y el cuidado hacia el otro. Buenos Aires, 1900-1940”. Ponencia presentada en Jornadas La enfermería universitaria en la Argentina (1952-1969), Universidad Nacional de José C. Paz.

Fiorucci, F. (2014). "Maestros para el sistema de educación pública. La fundación de escuelas normales en Argentina (1890-1930)”. Revista Mexicana de Historia de la Educación, 2, (3), pp. 25-45.

García, S. (2006). "Ni solas ni resignadas: la participación femenina en las actividades científico- académicas de la Argentina en los inicios del siglo XX". Cuadernos Pagu (27), pp. 133-172.

Gómez Molla, R (2018). "Universitarias argentinas. Desafíos para contarlas”. Anuario del Instituto de Historia Argentina, 18, (1), pp. 1-22

Heinz, F. M. (2011). “Nota sobre o uso de anuários sociais do tipo Who’s Who em pesquisa prosopográfica”. En F. M. Heinz, (org.) Historia social de las élites. São Leopoldo: Oikos.

Lionetti, L. (2007) La misión política de la escuela pública: la formación de los ciudadanos en Argentina, 1870-1916. Buenos Aires: Editorial Miño y Dávila.

Lionetti, L. (2018). "Revisitando la tradición normalista. Diálogos entre el peso de la formación y la perspectiva de género”. En L. G. Rodríguez y G. Soprano (editores), Profesionales e intelectuales de Estado. Análisis de perfiles y trayectorias en la salud pública, la educación y las fuerzas armadas. Rosario: Prohistoria, pp. 69-94.

Lobato, M. Z. (2007). Historia de las trabajadoras en la Argentina (1869-1960). Buenos Aires: Edhasa.

Maristany, J. (1998). "Maestras que escriben: entre el aula, el público y la academia”. La Aljaba, (III), 177-197.

Napolitano, A. P. (1972) (edit.). Quién es quién en La Plata (Argentina) 1972. La Plata: Napolitano Ed.

Pareto, V. (1980) [1916]. Forma y equilibrio sociales. (Extracto del Tratado de Sociología General), Madrid: Alianza.

Queirolo, G. A. (2018). Mujeres en las oficinas. Trabajo, género y clase en el sector administrativo (Buenos Aires, 1910-1950). Buenos Aires: Biblos.

Reyna Almandós, M. E. G. de et. al. (1938). La Escuela Normal Nacional Mary O' Graham de La Plata. Obra escrita en celebración de su cincuentenario. 1888- 13 agosto- 1938. Homenaje del Centro "Mary O' Graham" La Plata.

Rodríguez, L. G. (2018). “Maestro, inspector e intelectual: la biografía de Juan Francisco Jáuregui (1870- 1960)". En F. Fiorucci y L. G. Rodríguez, (comp.) Intelectuales de la educación y el Estado: maestros, médicos y arquitectos, Bernal: Universidad Nacional de Quilmes, pp. 45-78.

Rodríguez, L. G. (2018a). "El Estado en La maestra normal (1914): las instituciones educativas nacionales en las provincias y su impacto social y cultural”. PolHis, 22, (11), pp. 55-82. 
Rodríguez, L.G. (2018b). "Normalistas y católicos: trayectorias de un grupo profesional e intelectual durante la segunda mitad del siglo XX”. En L. G. Rodríguez y G. Soprano, (editores) Profesionales e intelectuales de Estado. Análisis de perfiles y trayectorias en la salud pública, la educación y las fuerzas armadas. Rosario: Prohistoria, pp. 185-204.

s/a (1955). Quién es Quién en la Argentina. Biografias contemporáneas. Buenos Aires: Ed. Guillermo Kraft Ltda.

s/a (1958-59). Quién es Quién en la Argentina. Biografias contemporáneas. Buenos Aires: Ed. Guillermo Kraft Ltda.

Vignoli, M. (2015). "Trayectoria educativa y prácticas asociativas de una tucumana de entre siglos: Margarita Todd, maestra normalista”. Historia y memoria, (11), pp. 123- 149.

Zanotti, J. L. (1960). El normalismo. Recuperado de http://luiszanotti.com.ar/normalismo.htm

\section{Notas}

1 Los analistas coinciden en que fue con los italianos Gaetano Mosca, Vilfredo Pareto y el alemán Robert Michels, que se configuró por primera vez un campo de reflexión científica sobre las élites. Pareto, en su Tratado de Sociología General explicaba: "Por lo tanto, supongamos que en todas las ramas de la actividad humana se atribuye a cada individuo un índice que indica sus cualidades, más o menos del mismo modo que se asignan puntos en los exámenes, en las diferentes materias que las escuelas enseñan. Por ejemplo, asignaremos 10 puntos a quien se destaca en su profesión. Al que no ha conseguido tener ni un solo cliente, le asignaremos 1 , con el fin de poder asignar 0 al que es realmente un cretino. A quien supo ganar millones, lo haya hecho bien o mal, le asignaremos 10. A quien gana millares de francos, le atribuiremos 6 (...) y así sucesivamente, para todas las ramas de la actividad humana (...) por consiguiente, formamos una clase con los que tienen los índices más elevados en la rama en que despliegan su actividad, y asignamos a esta clase el nombre de élite (Pareto, [1916]1980, p. 68-69).

2 Al parecer, el último Quién es Quién fue editado por Kraft en el año 1968. Luego salieron ediciones sin continuidad, intentando suplir la ausencia de estas primeras.

3 Por ejemplo, en la edición de 1958- 1959, las categorías profesionales que aparecían eran: abogados; agricultores, ganaderos y hacendados; agrimensores; antropólogos, arqueólogos, geógrafos y geólogos; arquitectos; actores y autores teatrales y cinematográficos; astrónomos; aviadores civiles, militares y navales; ceramistas; comerciantes; contadores públicos; dentistas; deportistas; dibujantes; diplomáticos; doctores (bioquímica y farmacia, en ciencias diversas, en ciencias económicas, en ciencias físico- matemáticas, en ciencias naturales, en derecho, en farmacia, en filosofía y letras, en jurisprudencia, en medicina, en química, en teología); electrotécnicos; escenógrafos; escribanos públicos; escritores; escultores; farmacéuticos; funcionarios públicos; grabadores; historiadores; industriales; ingenieros (agrónomos, civiles, electricistas, hidráulicos, industriales, maquinistas, mecánicos, aeronáuticos, militares, navales, químicos y textiles); magistrados; marinos; martilleros públicos; médicos, médicos (cirujanos, legistas y veterinarios); militares; músicos; periodistas; pintores; profesores de arte; profesores de enseñanza secundaria, normal y especial; profesores universitarios; y sacerdotes.

4 Incluso en los casos en que aparecían maestros sin título de profesores, eran incluidos en el ítem "profesores", dando cuenta de cuál era la profesión más prestigiosa para los editores. Este era el caso del maestro Juan F. Jáuregui de La Plata. Sobre la biografía completa de este maestro ver Rodríguez (2018).

5 Napolitano agradecía el auspicio brindado por la Asociación Pro Rehabilitación Infantil La Plata (APRILP). Lo recaudado por la venta del libro era para financiar el centro de rehabilitación integral de lisiados de la Asociación.

6 Algunas de ellas tenían dos títulos universitarios, pero hemos decidido contar solo el primer título. Estas estadísticas coinciden en líneas generales con las que presenta Gómez Molla (2018) sobre egresadas de la UNLP.

7 Como los mismos autores del libro explicaban, no habían podido incluir a todos los "notables" de la ciudad. Entre las ausentes estaban, por ejemplo, la maestra Sara del Carmen Ugazzi, que tenía una actuación destacada en la ciudad y muchos puntos en común con el resto de las biografiadas (Rodríguez, 2018).

8 Sobre los comienzos del normalismo, ver, entre otros, Alliaud (2007); Lionetti (2007); Fiorucci (2014); Rodríguez (2018a).

9 Mercader aparecía en el libro como soltera con dos hijos, pero analizando otras fuentes observamos que estaba separada, estatus civil que no se mencionaba en el Quién es Quién.

10 Hemos caracterizado en otro trabajo a un grupo de maestros y profesores varones egresados de la EN "Mariano Acosta" de la Capital Federal, que exhibían trayectorias como intelectuales y altos funcionarios del Estado nacional (Rodríguez, 2018b). 